\title{
Is Schumpeterian "Creative Destruction" a Plausible Source of Endogenous Real Business Cycle Shocks?
}

\author{
Kerk L. Phillips* \\ Department of Economics \\ P.O. Box 22363 \\ Brigham Young University \\ Provo, UT 84602-2363 \\ phone: (801) 378-5928 \\ fax: (801) 378-2844 \\ email: kerk_phillips@byu.edu
}

\author{
Jeff Wrase \\ U.S. Senate Joint Economic Committee \\ G-01 Dirksen Senate Office Building \\ Washington, DC 20510 \\ phone: (202) 224-2335 \\ email: jeff_wrase@jec.senate.gov
}

January 2004

JEL Codes: E32, O30, O40

\footnotetext{
* We wish to thank Val Lambson for helpful input. Participants at the 1999 Theories and Methods in Macroeconomics Conference at the University of Quebec at Montreal, the 2000 Conference on Growth and Business Cycles in Theory and Practice at the University of Manchester, the 2000 World Congress of the Econometric Society, and the 2001 Far East Meetings of the Econometric Society provided helpful comments on earlier drafts. Funding for travel and presentation of this research from the Federal Reserve Bank of Philadelphia and from the J. Fish Smith Endowed Chair in Free Markets is gratefully acknowledged.
} 


\begin{abstract}
This paper looks at the linkages between growth and business cycles by bringing together two strands of literature. We incorporate a quality ladders engine of growth into an otherwise standard real business cycle model. Our fundamental question is, can Schumpeter's creative destruction process which leads to lumpy technological improvement over time also generate realistic business cycles? We use a standard real business cycle approach to solve for rules of motion in our state variables and proceed to generate artificial time series. We compare the statistical properties of these series with their historical counterparts to determine if the model mimics the real world closely.

One advantage our approach has over the standard approach is that the trend component is included in our artificial series just as it is in the data. Hence, we are not tied to any particular filtering method when we compare simulations with the real world data.

We find that Schumpeterian fluctuations alone cannot generate realistic business cycles. We also find, however, that a model with both Schumpeterian and standard RBC shocks performs better in many dimensions than a model relying on standard RBC shocks alone.
\end{abstract}




\section{Introduction}

Dynamic general equilibrium models have proved to be valuable tools for examining both economic growth and fluctuations. One class of these models - the Schumpeterian or "quality ladders" models - focuses on explaining observed smooth growth trends. Segerstrom, Anant \& Dinopoulos (1990), Grossman \& Helpman (1991), and Aghion \& Howitt (1992) first introduced this literature in their seminal papers. In addition, there have been numerous extensions of the basic quality ladders model, focusing on innovation versus imitation, North-South trade patterns, and other related topics. ${ }^{1}$

Schumpeterian models have the advantages that they are rigorously based in microeconomic theory and have a great deal of intuitive appeal. In this literature, growth is driven endogenously by attempts to innovate and climb up the quality ladder to capture a stream of monopoly profits. Attention is normally focused on the steady state, where growth is smooth over time due to a large number of independent, but identical innovators each targeting a unique good. Growth for any given good, proceeds in a lumpy fashion with discrete jumps in quality occurring randomly over time, but the law of large numbers leads to smooth aggregate growth.

A second class of models focuses on explaining the behavior of economic aggregates over the course of the business cycle. Usually referred to as real business cycle (RBC) models, early work began with seminal papers by Kydland \& Prescott (1982) and Long \& Plosser (1983). Again, numerous papers have extended this literature to the examination of aggregate labor behavior, monopolistic competition, monetary aggregates, and various other topics. ${ }^{2}$

The RBC methodology generally involves building a general equilibrium model, with changes in productivity (and, more recently, other economic fundamentals) driving aggregate behavior. These models are capable of generating artificial data that mimic observed business cycles. Unlike

${ }^{1}$ For an extensive overview of this literature see Grossman and Helpman (1991) and Aghion and Howitt (1998).

2 For an excellent overview of the RBC literature see Cooley (1995). 
the Schumpeterian literature, attention is focused on the off-steady-state high-frequency behavior of aggregate economic variables.

In practice, $\mathrm{RBC}$ models are typically transformed into a stationary variant and solved numerically to yield stationary laws of motion for endogenous variables as functions of endogenous states and exogenous driving processes. A stationary model economy is then simulated and evaluated by comparing properties of data drawn from the model with data drawn from actual economies. Since the focus of RBC models is on high-frequency fluctuations and not on economic growth, the growth component is usually ignored. However, in order to compare the artificial economy with real world data it is necessary to remove the growth component from the real world data; i.e. to detrend it. While many business cycle stylized facts are invariant to the filter used, there are some important facts that are not ${ }^{3}$.

Generally in RBC models, the source of shocks is an exogenously imposed sequence of large and volatile productivity shocks. A common specification of such shocks is a simple AR(1), and there is little or no economic theory involved in the specification of the driving process. Moreover, there is increasing skepticism that technology shocks, measured by Solow residuals, are a major source of business cycle fluctuations. As King and Rebelo (1998) point out "A key difficulty is that typical estimates of Solow residuals imply a probability of technical regress on the order of $40 \%$, which seems implausible to most economists."

This paper integrates the two branches of literature identified above: the RBC literature, which focuses on detrended, high frequency fluctuations; and the Schumpeterian literature, which focuses on low-frequency growth trends. The objective is to construct a dynamic general equilibrium model with an endogenous driving process for business cycles derived from microeconomic primitives, and with high- and low-frequency movements in economic aggregates that mimic those observed in the U.S. economy.

${ }^{3}$ See Canova (1998). 
The endogenous growth component of the model is included in simulations, which create artificial data. Properties of the artificial data are then compared to like properties of their real data counterparts to evaluate the model's performance. ${ }^{4}$

An important feature of the model is that growth and cyclical properties of data stem from a common source - endogenous innovations to technology. Technical regress is not necessary for business cycle fluctuations in the model. Rather, the endogenous movements of resources between goods production and technological advancement gives rise to cyclical fluctuations, as well as lower frequency movements in key macroeconomic variables. In principle, the model does not require large and variable technology shocks that imply high likelihoods of technical regress to explain business cycles. Rather, endogenous improvements in technology and the diffusion of the improvements into production of final goods can help explain both growth and cycles.

\section{Methodology}

Our methodology is as follows. We incorporate features of the Schumpeterian growth literature into a real business cycle model of the macroeconomy. We interpret what are usually called increases in quality in the Schumpeterian literature as increases in productivity, and we keep the quality of goods constant over time. If a small number of industries are assumed, this gives rise to aggregate growth in technology that is "lumpy" and can therefore serve as a driving process for business cycles.

The model is evaluated by: linearizing agents' Euler equations, with market clearing conditions imposed; numerically solving the model for endogenous variables as functions of endogenous states and exogenous shocks; simulating the model to generate sequences of macroeconomic aggregates; comparing properties of data generated by the model with properties of data drawn from the U.S. economy at both high- and low- frequencies.

${ }_{4}$ Note that since growth is endogenous in the model, the choice of which particular detrending method to use is less critical than in a protoypical RBC model. 
There are two sources of shocks in the model. One (denoted $A$ ) is a sequence of random draws to determine success or failure of potential innovators who invest resources in basic research and development (R\&D) to influence their success probabilities. In aggregate the size of this shock goes to zero as the number of independent industries assumed is increased. A second source of shocks (denoted z) is innovations to labor productivity governed by a process typically used in RBC models. This set-up has the advantage of nesting both the pure RBC model and the Schumpeterian model as special cases. To examine the dynamics of the RBC model we can set the number of intermediate goods to a very large number (like 1,000,000) and virtually all fluctuations will come from the exogenous shocks. Similarly, we can set the variance of the exogenous shocks to zero and the number of industries to a small number to examine the dynamics of the pure Schumpeterian case.

\section{A Comparison with Other Dynamic Schumpeterian Models}

Our approach is related to recent papers by Andolfatto \& MacDonald (1998), Collard (1999), Freeman, Hong \& Peled (1999), and Ozlu (1996) which also focus on dynamic implications of endogenous growth models. There is also an expanding literature on "Schumpeterian waves", which looks at the behavior of the economy in response to large but infrequent movements in basic technology. Early work by Cheng \& Dinopoulos (1992 \& 1996) looked at these longer-run fluctuations. Aghion \& Howitt (1998) devote a portion of their book to this phenomenon as well ${ }^{5}$. Wälde (2002) examines the implications of Schumpeterian growth in a continuous time framework, but does not calibrate or compare model generated data with real world data.

Collard and Ozlu each consider extensions of a standard RBC model to include endogenous growth through human capital accumulation effects of learning-by-doing. Ozlu considers labor market implications of allowing learning-by-doing effects on human capital, while Collard considers implications for the autocorrelation of output growth and impulse response functions in the trendreverting component in output. These authors find improvements in quantitative implications of

\footnotetext{
5 Chapter 8, especially section 8.4.
} 
RBC models augmented to include learning-by-doing effects over standard RBC models without human capital features. Our analysis is similar to those performed by Collard and Ozlu in two respects. First, we also consider business cycle implications of an RBC model augmented to include an endogenous growth mechanism. Second, as in Collard's analysis, we consider implications of our model for fluctuations in key variables at various frequencies including, but not limited to, business cycle frequencies. Our model differs from theirs, however, in an important way. While Collard and Ozlu essentially provide a model of an endogenous mechanism for the propagation of exogenous technology shocks, we model both propagation of shocks and the shocks themselves. That is, we present a model that accounts for how shocks to technology arise, as well as how they may be propagated and diffused through time.

Closer to the spirit of our analysis is the work by Andolfatto \& MacDonald, and by Freeman, Hong \& Peled. The latter set of authors construct a model of large and costly technological changes which give rise to deterministic cycles and long run growth. Their economy requires a sufficiently large amount of capital, diverted from consumption and physical investment, for birth of a technological innovation. Then, when an innovation occurs, capital is more highly valued in physical investment than in R\&D investment. Consequently, resources flow away from R\&D and toward final goods production. As the marginal product of capital using existing technology fades through time, resources subsequently flow back toward consumption and the production of R\&D innovations. These flows of capital give rise to endogenous movements in consumption and investment patterns within each fixed-length innovation cycle. Our analysis similarly accounts for endogenous movements in key macroeconomic variables within innovation cycles, but also explicitly models innovation cycles of random durations. ${ }^{6}$ In addition, when exploring quantitative predictions of our model relative to quantitative properties of actual data, we explicitly consider movements in key

${ }^{6}$ Another difference between our model and the one constructed by Freeman, Hong, and Peled is that our model considers labor, rather than capital, as the input to the R\&D process. We include only labor to simplify the analysis but are free to enter capital into the R\&D process as well. 
macroeconomic variables at well-defined frequencies. In contrast, Freeman, Hong, and Peled are agnostic about the frequency one should look at in actual data for the innovation-driven cyclical patterns of movements that their model predicts.

The analysis of Andolfatto \& MacDonald is close to that in this paper in that they consider fluctuations and growth in key macroeconomic aggregates arising from the discovery and diffusion of technological innovations. As in our model, Andolfatto \& MacDonald have growth arising from technological discovery and use, and fluctuations arising from diffusion of applied, or frontier, research. Some type of diffusion mechanism is required in each model to smooth out what would otherwise be unrealistic spikes in economic aggregates from infrequent, possibly large, technological innovations springing up from applied research.

Andolfatto \& MacDonald consider a diffusion mechanism involving imitation and learning how to use new technology, which diverts resources from production. Agents choose the amount of resources to devote to various imitation and learning possibilities available to them, the outcomes of which are random. With such a mechanism, the authors compare Hodrick-Prescott filtered series (in levels, not deviations from filtered series) from actual data with like series drawn from their model.

The model in this paper has no such mechanism for innovation and diffusion, though previous work has focused on a similar diffusion process. Our analysis differs from Andolfatto \& MacDonald's in the frequencies of movements in macroeconomic variables considered. Our model is an attempt at simultaneously accounting for growth and business cycle fluctuations. Consequently, we consider movements in macroeconomic variables at various frequencies, including those that arise at business cycle frequencies. We do not restrict attention to data movements at frequencies at or below those at which major innovations diffuse, as do Andolfatto \& MacDonald.

\section{A Dynamic General Equilibrium Schumpeterian Model}

In this section, insights of the Schumpeterian or "quality ladders" growth models are incorporated into a discrete-time stochastic general equilibrium model of the real business cycle tradition. Since it is well known that the equilibrium from Schumpeterian growth models is socially suboptimal, we proceed to examine the competitive equilibrium. First, we examine the behavior of 
households, then that of production firms, and finally the behavior of research firms. Imposing aggregate resource constraints and market clearing conditions closes the model. ${ }^{7}$

The model contains households, production firms, and research firms. Each infinitely lived household is endowed with one unit of labor each period supplied to firms at wage $w$. Households also accumulate physical capital, $K$, over time, which they rent to firms each period at rental rate $r t$. In addition to physical capital, households buy and sell equity shares in two types of existing firmsproduction and research firms-in $I$ different intermediate industries. These shares influence the household's budget by generating dividends and capital gains or losses. There is also a final goods sector, which we assume is perfectly competitive and generates no profits. For simplicity, we abstract from buying and selling of these firms' equities ${ }^{8}$.

In each period there is a single production firm in each intermediate industry with an exclusive right to a particular level of production technology, $A_{i}$, that is some factor $\theta>1$ better than the closest competitor. This production firm enjoys monopoly power and earns monopoly rents during the current period, and possibly many future periods, until a firm with even better technology replaces it. The production firms hire labor and rent capital to produce intermediate goods, and pay out profits as dividends to shareholders each period. Final goods are produced by combining intermediate goods.

There also exists a single new research firm for each intermediate industry, which incorporates with the intent of displacing the current production firm in its role of monopolist. The research firm issues equity shares and uses the proceeds to hire units of labor to attempt an innovation. If successful, the research firm discovers a technology that is a factor $\theta$ better than the current production firm and begins production as the monopolist next period. If unsuccessful, the firm ceases to exist and its equity shares become worthless. We account for successes and failures

${ }^{7}$ A listing of notation and variables used in the model is contained in Table 1.

8 The assumption is innocuous because these equities would have zero prices. 
across the $i$ industries with an $I$-dimensional vector $\mathbf{S}^{\prime}$, with element $S_{i}^{\prime}=1$ if a research firm succeeds in the current period and $S_{i}^{\prime}=0$ if not. If $S_{i}^{\prime}=1$, then today's research firm in industry $i$ becomes the production firm tomorrow with technology $A_{i}^{\prime}$ that is a factor $\theta$ better than its predecessor $^{9}$

There is also an aggregate random shock to productivity in the model, unrelated to any of the $A_{i}{ }^{\prime} S$ which we denoted $z$. This exogenous shock is to the productivity of labor in the intermediate goods producing firms' production functions. We include such shocks to allow for shocks to productivity unrelated to actual movements in technology, such as oil price shocks, changes in marginal tax rates, changes in government regulation of production processes, or similar nontechnology shocks. This shock to productivity, assumed to be common to all $I$ intermediate good producers, is of the form used in standard RBC models. One of our interests will be the extent to which, by allowing for random innovations in $R \& D$, the model does not require productivity shocks that are as persistent and volatile as those typically employed in RBC models to explain business cycle fluctuations.

The timing of information, shocks, and activities in the economy is as follows. Agents begin a period with capital stock $K$ knowing research and shock realizations $\mathbf{A}^{10}$, and $z$. At the beginning of the period, factor and equity markets open and clear. Firms rent capital from households, and real rental rate $r$ is determined. Firms also hire labor from households, and a real wage $w$ is determined. Research firms issue shares, and prices of those shares, $\mathbf{q}^{R}$ (also a vector), are determined, and production firms issue shares, and their prices, $\mathbf{q}^{P}$, are determined. Following input and funding acquisitions, production of goods and research occurs and the research results and random shocks $\mathbf{A}^{\prime}$,

9 We adopt the notation convention that variables without a prime denote current period values and variables with a prime denote next-period values. Additionally, bold letters are used to denote i-dimensional vectors of variables.

10 This is a vector containing all the $A_{i}$ shocks 
and $z^{\prime}$ are revealed. Subsequently, at the end of the period, factor payments $W$ and $r K$ are made, production-firm profits $\pi$ are distributed to shareholders, next period's capital stock $K$ is chosen, and consumption occurs. We now turn to decisions made by the household, production firms, and research firms.

\section{The Household's Problem}

A representative household enters a period with capital $K$ carried over from the previous period and a normalized unit labor endowment. ${ }^{11}$ The household also owns stocks of equity shares in last period's production and research firms, denoted by share vectors $\mathbf{P}$ and $\mathbf{R}$. The household knows the following: the current levels of technology, A, to be employed by this period's production firms, the current random productivity shock, $z$, and whether last period's research firms succeeded or failed, the vector $\mathbf{S}$. Taking prices $r, w, \mathbf{q}^{P}, \mathbf{q}^{R}$, and the probabilities of success by the current research firms, $\rho$, as given, the household chooses new stocks of equities $\mathbf{P}^{\prime}$ and $\mathbf{R}^{\prime}$ to carry over to next period.

After production is completed and next period's values for technology, $\mathbf{A}^{\prime}$, and $z^{\prime}$, are revealed, the household chooses a level of capital, $K$, to carry into next period. Consumption then occurs according to the household's choices and budget constraint.

The value function for the household is thus:

$$
V(K, \mathbf{P}, \mathbf{R} ; \mathbf{\Omega})=\operatorname{Max}_{P^{\prime}, R^{\prime}} E\left\{\operatorname{Max}_{K^{\prime}} u(C)+\beta V\left(K^{\prime}, \mathbf{P}^{\prime}, \mathbf{R}^{\prime} ; \mathbf{\Omega}^{\prime}\right)\right\}
$$

where: $C=w+(1-\delta+r) K-K^{\prime}+\sum_{i=1}^{I}\left\{\left[\pi_{i}+q_{i}^{P}\right]\left[\left(1-S_{i}\right) P_{i}+S_{i} R_{i}\right]-q_{i}^{P} P_{i}^{\prime}-q_{i}{ }^{R} R_{i}{ }^{\prime}\right\}, u(\mathrm{C}) \quad$ is the momentary utility function, $\beta$ is the discount factor, $\boldsymbol{\Omega}=\left\{w, r, \mathbf{q}^{R}, \mathbf{q}^{P}, \boldsymbol{\rho}, \mathbf{S}, \mathrm{A}, z\right\}$ is an information set, and $E$ is the expectation operator given information available at the beginning of the period. $\rho$ in the information set represents the vector of industry R\&D success probabilities. S represents the

11 The household supplies its endowment inelastically and therefore receives wages $w^{*} 1$. The labor endowment is divided between research and production firms' activities. 
vector of industry R\&D success indicator variables, taking values of 1 if a success occurs, and 0 if failure occurs.

For industry i, $\rho_{i}$ is the probability of an applied research firm successfully innovating in the current period to become next period's intermediate goods producer with an improved technology. We explicitly model the innovation probabilities below in the discussion of the research firms' problems. What is relevant for the household's decision is that with probability $\rho_{i}$ a share in today's industry $i$ research firm will pay off next period. If today's research firm pays off next period, then a share in that industry's current intermediate goods producing firm will not pay off next period because it is replaced by the current period's successful innovator. Correspondingly, with probability $1-\rho_{i}$, industry is current research firm is unsuccessful and won't pay off next period. In that case, the current intermediate goods producer remains as next period's producer providing payoffs on its shares.

The envelope conditions from the household's problem consist of $I$ conditions each for the shares $P_{i}$ and $R_{i}$, and a condition for capital stock $K$ given, respectively, by:

$$
\begin{aligned}
& V_{P}^{i}(K, \mathbf{P}, \mathbf{R} ; \mathbf{\Omega})=E\left\{u_{C}(C)\right\}\left(\pi_{i}+q_{i}^{P}\right)\left(1-S_{i}\right) \mathrm{i}=1,2, \ldots, I \\
& V_{R}^{i}(K, \mathbf{P}, \mathbf{R} ; \mathbf{\Omega})=E\left\{u_{C}(C)\right\}\left(\pi_{i}+q_{i}^{P}\right) S_{i} \mathrm{i}=1,2, \ldots, I \\
& V_{K}(K, \mathbf{P}, \mathbf{R} ; \mathbf{\Omega})=E\left\{u_{C}(C)\right\}(1-\delta+r)
\end{aligned}
$$

The Euler equations corresponding to the household's choices consist of $I$ conditions each for next period shares $P_{i}^{\prime}$ and $R_{i}^{\prime}$, and a condition for next period's capital stock $K^{\prime}$ given by:

$$
\begin{aligned}
& E\left\{u_{C}(C)\right\}\left(-q_{i}^{P}\right)+\beta E\left\{V_{P}^{i}\left(K^{\prime}, \mathbf{P}^{\prime}, \mathbf{R}^{\prime} ; \mathbf{\Omega}^{\prime}\right)\right\}=0 \text { for } \mathrm{i}=1,2, \ldots, I \\
& E\left\{u_{C}(C)\right\}\left(-q_{i}^{R}\right)+\beta E\left\{V_{R}^{i}\left(K^{\prime}, \mathbf{P}^{\prime}, \mathbf{R}^{\prime} ; \mathbf{\Omega}^{\prime}\right)\right\}=0 \text { for } \mathrm{i}=1,2, \ldots, I \\
& u_{C}(C)(-1)+\beta V_{K}^{i}\left(K^{\prime}, \mathbf{P}^{\prime}, \mathbf{R}^{\prime} ; \mathbf{\Omega}^{\prime}\right)=0
\end{aligned}
$$

Combining envelope and Euler equations gives the following $2 \mathrm{I}+1$ system of equations:

$$
E\left\{u_{C}(C)\right\} q_{i}^{P}=\beta\left(1-\rho_{i}\right) E\left\{u_{C}\left(C^{\prime}\right)\left(\pi_{i}^{\prime}+q_{i}^{P^{\prime}}\right) \mid A_{i}=\theta\right\} \quad \mathrm{i}=1,2, \ldots, I
$$




$$
\begin{aligned}
& E\left\{u_{C}(C)\right\} q_{i}^{R}=\beta \rho_{i} E\left\{u_{C}\left(C^{\prime}\right)\left(\pi_{i}{ }^{\prime}+q_{i}^{P^{\prime}}\right) \mid A_{i}=1\right\} \quad \mathrm{i}=1,2, \ldots, I \\
& u_{C}(C)=\beta E\left\{u_{C}\left(C^{\prime}\right)\left(1-\delta+r^{\prime}\right) \mid \mathbf{A}^{\prime}, z^{\prime}\right\}
\end{aligned}
$$

where expectation operator $E\{\mathrm{x} \mid \mathrm{y}\}$ denotes the expectation of $\mathrm{x}$ given all the information available at the beginning of the period, plus additional information revealed after the beginning of the period that is contained in $\mathrm{y}$.

The laws of motion governing each industry's applied technology level $A_{i}$, applied research success index $S_{i}$, exogenous technology shock z, and basic technology level $B_{i}$, known to the household, are:

$$
\begin{aligned}
& A_{i}{ }^{\prime}, S_{i}{ }^{\prime}= \begin{cases}\theta A_{i}, 1 & \text { with probability } \rho_{i} \\
A_{i}, 0 & \text { with probability } 1-\rho_{i}\end{cases} \\
& z^{\prime}=\psi z+\eta^{\prime} ; \text { where } \eta^{\prime} \text { is distributed Normal }\left(0, \sigma^{2}\right)
\end{aligned}
$$

The endogenous choices and random shocks governing the applied R\&D success probabilities $\rho_{i}$ are discussed in detail below when the R\&D firms' choice problems are discussed. The $z$ shocks are the productivity shocks discussed earlier.

\section{Production of Final Goods}

Final goods production is an Armington aggregator of all intermediate goods, and uses no capital or labor. ${ }^{12}$

$$
Y=I \prod_{i=1}^{I} Y_{i}^{1 / I}
$$

Firms view the prices of intermediate goods as fixed, and a typical firm maximizes profits:

${ }^{12}$ We could take the usual approach and use this aggregator as a utility function expressing a preference for variety across the $I$ intermediate goods. Interpreting it as a final good, however, has the advantage of yielding a natural numeraire good for the calculation of real values. 


$$
\Pi_{F}=I \prod_{i=1}^{I} Y_{i}^{1 / I}-\sum_{i=1}^{I} p_{i} Y_{i}
$$

First-order conditions for the firm's problem yield:

$$
p_{i} Y_{i}=\frac{Y}{I}
$$

This shows that all intermediate firms earn the same amount of real revenue. Alternatively stated, regardless of the amount produced, expenditures on each intermediate good are equal.

\section{Production of Intermediate Goods}

The production firm produces output using a Cobb-Douglas production function with two sources of productivity variation, both of which are assumed to be labor augmenting:

$$
Y_{i}=K_{i}^{\alpha}\left[e^{z} A_{i} N_{i}\right]^{1-\alpha}
$$

Productivity variations come from productivity shocks, $z$, along with the endogenous growth shocks $A_{i}$

The monopolistic production firm faces a downward sloping demand curve defined by (2.8). However, there is a potential competitor that places limits on the price the monopolist will charge. The previous producer of the good has access to a technology that is $1 / \theta$ as productive as the current firm's. The current firm will never charge a price that exceeds its marginal cost by more than a factor of $\theta^{1-\alpha}$. To do so would be to surrender production to the previous producer. It can easily be shown that the marginal cost for the current firm is:

$$
\left(\frac{1}{e^{z} A_{i}}\right)^{1-\alpha}\left[\left(\frac{\alpha}{1-\alpha}\right)^{1-\alpha}+\left(\frac{1-\alpha}{\alpha}\right)^{\alpha}\right] w^{1-\alpha} r^{\alpha},
$$

Similarly, the marginal cost for its closest competitor is:

$$
\left(\frac{\theta}{e^{z} A_{i}}\right)^{1-\alpha}\left[\left(\frac{\alpha}{1-\alpha}\right)^{1-\alpha}+\left(\frac{1-\alpha}{\alpha}\right)^{\alpha}\right] w^{1-\alpha} r^{\alpha}
$$

Hence, the optimal price for the firm is to charge a multiplicative markup of $\theta^{1-\alpha}$ over marginal cost. 
Standard optimality conditions for the firm reveal that it divides revenues between payments to labor, capital, and dividends according to:

$$
\begin{aligned}
& w N_{i}=\frac{1-\alpha}{\theta^{1-\alpha}} p_{i} Y_{i}=\frac{1-\alpha}{\theta^{1-\alpha} I} Y \\
& r K_{i}=\frac{\alpha}{\theta^{1-\alpha}} p_{i} Y_{i}=\frac{\alpha}{\theta^{1-\alpha} I} Y \\
& \pi_{i}=\frac{\theta^{1-\alpha}-1}{\theta^{1-\alpha}} p_{i} Y_{i}=\frac{\theta^{1-\alpha}-1}{\theta^{1-\alpha} I} Y
\end{aligned}
$$

These distribution equations show that capital, labor, and profits are identical for all intermediate firms regardless of the level of technology they use. The aggregate values are, then, $K=I K_{i}$, $N=I N_{i}$ and $\pi=I \pi_{i}$. Substituting these values into (2.9) and (2.6), the production of final goods can be written as an aggregate production function of the form:

$$
\begin{gathered}
Y=I \prod_{i=1}^{I}\left[K_{i}^{\alpha}\left(e^{z} A_{i} N_{i}\right)^{1-\alpha}\right]^{1 / I}=K^{\alpha}\left(e^{z} A N\right)^{1-\alpha} \\
\text { where } A \equiv \prod_{i=1}^{I} A_{i}^{1 / I}
\end{gathered}
$$

This shows how we can collapse the production of intermediate and final goods into a single aggregate production function.

Given the manner in which the $A_{i}$ evolve in (2.4), and the aggregation in (2.11), aggregate technology, $A$, evolves according to the following Binomial law of motion:

$$
A^{\prime}=A \theta^{J / I} ; \text { with } J \text { distributed as } \operatorname{Binomial}(I, \rho)
$$

The Research Firm's Problem 
Each period, a single research firm springs into existence in each industry. ${ }^{13}$ It sells equity shares, normalized to a quantity of one, to the household at price $q_{i}^{R}$ and uses the proceeds to hire labor. Taking prices $w$ and $q_{i}^{R}$ as fixed, the firm chooses the amount of labor to hire by solving:

$$
\operatorname{Max}_{L_{i}} \Pi_{R}=\rho_{i} E\left\{\frac{V_{i}^{\prime}}{1+r} \mid S^{\prime}=1\right\} \text { s.t. } w L_{i} \leq q_{i}{ }^{R}
$$

where $V_{i}^{\prime}=\pi_{i}{ }^{\prime}+q_{i}^{P}{ }^{\prime}$ is the reward for a successful innovation, and $\rho_{l}$ is the probability of success.

The reward for success consists of the expected present value of the stream of profits given that a success occurs, which happens with probability $\rho_{i}$. Appendix 1 shows that this reward can be written as:

$$
V_{i}^{\prime}=\frac{\theta^{(1-\alpha)}-1}{\theta^{(1-\alpha)}} \sum_{s=t+1}^{\infty} \frac{1}{I} Y_{s} d_{i s}
$$

where $d_{i s}$ is a discount factor defined in the appendix. The right side of equation (2.14) is simply the discounted sum of all future profits in the industry, with discounting inclusive of time and probabilities of loss of the profit stream in future periods.

We model the research firm as hiring labor inputs that are used to produce research tries. In the limit, with a continuous measure for the tries, the probability of success comes from a Poisson distribution. As shown in Lambson and Phillips (1999), this gives the following functional form for an industry's applied R\&D success probability:

$$
\rho_{i}=1-\exp \left\{-\kappa L_{i}\right\}
$$

where $\kappa$ is the "ease" of doing research. For the sake of tractability we are assuming that all industries have the same level of ease of $R \& D$, i.e. that there is no advantage or disadvantage to doing $R \& D$ in an industry that is higher or lower on the quality ladder than the average.

${ }^{13}$ For $\mathrm{s}$ discussion of the issues involved with assuming more that one R\&D firm in such a discrete time framework see Lambson \& Phillips (2003). 
In a symmetric equilibrium, arising when all firms have the same probability function for $\rho_{i}$, the reward for success in (2.14) will be the same for all firms. All firms then face an identical problem. The solution to the problem is for the firm to hire the amount of labor it can afford, given the constraint from equity sales. Consequently, $q_{i}^{R}=w L_{i}$ for each industry and aggregate employment by all research firms is $L=I L_{i}$. In addition, since the expected revenue streams for all intermediate goods producers are the same, the prices of equities for all research and production firms are equal.

\section{Market-Clearing Conditions}

In addition to the Euler equations from the household and firms' problems, market clearing conditions must be satisfied. Clearing of the labor and capital markets requires:

$$
\begin{aligned}
& \sum_{i=1}^{I}\left[L_{i}+N_{i}\right]=L+N=1 \\
& \sum_{i=1}^{I} K_{i}=K
\end{aligned}
$$

and clearing of equity markets requires:

$$
\begin{aligned}
& P=P^{\prime}=1 \\
& R=R^{\prime}=1
\end{aligned}
$$

With these conditions, Walras' law ensures goods market clearing.

\section{The Transformed Model}

The model economy experiences growth in consumption and output per household due to the increases in $A$ over time. It will be convenient to work with a transformed model where the endogenous variables are all stationary. Since transformations to induce stationarity are commonly used, we delegate details to Appendix 2 and hereafter consider a transformed version of the model. Variables growing at the same rate as $A$ are transformed with division by $A$, and the transformed variables will be denoted with a caret so that, for example, $\hat{K} \equiv K / A$.

The transformed law of motion for $A$ is: 


$$
g_{A}{ }^{\prime} \equiv A^{\prime} / A=\rho(\theta-1)+1+\varepsilon^{\prime}
$$

where $\quad \varepsilon^{\prime}=[(J / I)-\rho](\theta-1), \quad J \quad$ is distributed Binomial $(I, \rho), \quad E\left\{\varepsilon^{\prime}\right\}=0, \quad$ and $\operatorname{Var}\left\{\varepsilon^{\prime}\right\}=\frac{\rho(1-\rho)}{I}(\theta-1)^{2}$

The law of motion for $z$ remains:

$$
z^{\prime}=\psi z+\eta^{\prime}
$$

with $\eta^{\prime}$ distributed $\mathrm{N}\left(0, \sigma^{2}\right)$.

We use a standard CES momentary utility function of the form, $u(C)=\frac{C^{1-\gamma}-1}{1-\gamma}$. Substituting for marginal utility and transforming household optimality conditions (2.1) - (2.3) gives:

$$
\begin{aligned}
& E\left\{\hat{C}^{-\gamma}\right\} \hat{q}^{P}=\beta(1-\rho) E\left\{\left[1+\left(\rho \frac{I-1}{I}+\frac{1}{I}\right)(\theta-1)+\frac{I-1}{I} \varepsilon^{\prime}\right]^{1-\gamma} \hat{C}^{\prime-\gamma}\left(\hat{\pi}^{\prime}+\hat{q}^{P \prime}\right)\right\} \\
& E\left\{\hat{C}^{-\gamma}\right\} \hat{q}^{R}=\beta \rho E\left\{\left[1+\rho \frac{I-1}{I}(\theta-1)+\frac{I-1}{I} \varepsilon^{\prime}\right]^{1-\gamma} \hat{C}^{\prime-\gamma}\left(\hat{\pi}^{\prime}+\hat{q}^{P \prime}\right)\right\} \\
& \hat{C}^{-\gamma}=\beta E\left\{\left[1+\rho(\theta-1)+\varepsilon^{\prime}\right]^{-\gamma} \hat{C}^{\prime-\gamma}\left(1-\delta+r^{\prime}\right)\right\}
\end{aligned}
$$

Substituting (2.16), (2.18) and (2.19) into the household's budget constraint and taking expectations gives:

$$
\hat{C}=\hat{w}+(1-\delta+r) \hat{K}+\hat{\pi}-\hat{K}^{\prime} g_{A}^{\prime}-\hat{q}^{R}
$$

The additional transformed equations from firms' decisions are:

$$
\begin{aligned}
& \hat{Y}=\hat{K}^{\alpha}\left[e^{z}(1-L)\right]^{1-\alpha} \\
& \hat{w}(1-L)=\frac{1-\alpha}{\theta^{1-\alpha}} \hat{Y} \\
& r \hat{K}=\frac{\alpha}{\theta^{1-\alpha}} \hat{Y} \\
& \hat{\pi}=\frac{\theta^{1-\alpha}-1}{\theta^{1-\alpha}} \hat{Y} \\
& \rho=1-\exp \{-\kappa L\}
\end{aligned}
$$




$$
\hat{q}^{R}=\hat{w} L
$$

Equations (3.1) - (3.12) define the dynamic model that we solve, parameterize, and simulate. Because the highly nonlinear nature of the system makes closed form solutions intractable, we consider a linear approximation of the system about its steady state.

\section{Calibration and Simulation}

We solve the system using the method of undetermined coefficients developed in Christiano (1990). Because we approximate about the model's steady state, we first need to solve for the steady state. The parameters and their values are listed in table 2 . There are six parameters which define the steady state: $\alpha, \beta, \gamma, \delta, \kappa$, and $\theta$. For consistency with existing RBC-model parameterizations, we set capital's share in output, $\alpha$, to .3 , the quarterly discount factor, $\beta$, to.995, and the quarterly depreciation rate, $\delta$, to .02 . We also set the autocorrelation coefficient on the $z$ shocks, $\psi$, to .95 .

$\theta$, the jump up the technology ladder, is set to 1.04877 , a value which sets the variance of $A$ innovations to the variance of $z$ innovations needed to drive a pure RBC version of our model. $\kappa$ and $\gamma$ are chosen to exactly fix two steady state values, the average quarterly growth rate of real output, and the user cost of capital, $r \delta$. We set average quarterly real growth equal to .00834, and $r \delta$ to .0062 , or $2.5 \%$ per annum, by setting $\kappa$ and $\gamma$ equal the appropriate values. ${ }^{14}$ Given the parameter values we have assigned, the steady state probability of success in applied R\&D is $\rho=.056$, which we take to be an empirically plausible and conservative value.

The standard deviation of technology shocks is set at .0184, similar to the value used in most RBC analyses. For example, using data from the U.S. economy in the post Bretton Woods era, Schlagenhauf and Wrase (1995) use a value of .014. Our objective is to see how the model, with substantially less reliance on auto-correlated productivity shocks than standard RBC models,

14 To see how $\gamma$ is chosen, consider the steady state version of equation (3.6): $1=\beta\left(\bar{g}_{A}{ }^{\prime}\right)^{-\gamma}(1-\delta+\bar{r})$. Note that it is necessary to pick a value of $\beta$ sufficiently large if we are to generate positive values for $\gamma$. 
performs in accounting for business cycle fluctuations observed in key macroeconomic variables. Given the parameter values we use the standard deviation of the innovations to $R \& D$ in (3.1) is .0184 when $I=1$. We are not, however, simply assuming the variability of the R\&D innovations. The variability of innovations to the evolution of $A$ in (3.1) depends on the probability of success in R\&D. In turn, the success probability depends endogenously on labor choices made by R\&D firms and households in the model. We cannot simply choose the standard deviation of innovations in applied $R \& D$ without restriction. One restriction is that the probability of success in the model must be an empirically plausible value.

Note that the model generates a series of growth rates. We can use these to construct a series for the level of technology, the $A$ 's, and then convert all the stationary, caret-bearing, variables to their non-stationary counterparts. Hence, simulation of the model generates data with both cyclical and growth components.

The model was simulated 1000 times using a sample of 200 observations, corresponding to 50 years of data. We filter both actual data drawn from the U.S. economy and model-generated data using two filters: the Hodrick-Prescott (HP) filter; and, to consider movements of variables at other than simply business cycle frequencies, a band-pass filter. We then compute statistical properties of the data, and compare properties of model-generated data with like properties of actual data. We focus on standard RBC measures of variability, cyclicality, and persistence, but consider more than the business cycle frequencies that are the sole focus of RBC analyses.

\section{Quantitative Results}

Table 3 presents business cycle moments summarizing behaviors of key macroeconomic aggregates for the U.S. economy over a sample period 1947:I to 2002:IV.15 We define output as real GDP, consumption as real consumption of services and non-durables, and investment as real investment in non-residential structures and equipment. As is well known, and as revealed in the

15 The data are real GDP, real consumption of services and nondurables, and real gross fixed investment in nonresidential structures and equipment. 
table, investment is close much more variable than output, with variability measured by standard deviations. Consumption has only three-quarters the variability of output. In addition, output is highly serially correlated, consumption is highly correlated with output contemporaneously and at one to two period leads and lags, and investment is not strongly correlated with output contemporaneously or at leads and lags.

The purpose of this paper is not necessarily to match all of these business cycle facts. While it would certainly be desirable to do so, our primary question is how well a model with endogenized shocks from a Schumpeterian framework performs relative to standard exogenous shock models. It is well-known that simple versions of such models cannot replicate all business cycle facts and require additional modeling details. With the exception of the endogenous $R \& D$ process, our model is quite basic and lacks many features needed to conform to measured movements. To answer our fundamental question, therefore, we proceed to solve and simulate several different versions of our model and compare them.

The first model we simulate is a simple RBC model with no R\&D process and a fixed supply of labor. Here there is only one source of shocks. In all other respects we treat the model exactly as the one outlined above. We assume a fixed rate of growth for $A$, rather than a stochastic one, for example, and add this trend into the simulated model when creating artificial data series. These series are then detrended using the same filters as table 3. The results of 1000 simulations of this model with 224 observations are reported in table 4 . The table shows the usual sorts of problems with such simple models. The volatility of consumption is too high, and the volatility of investment is too low. The auto-correlations of output over time are not too different from the US data, but the correlations of consumption and investment with leads and lags of output are very poor matches regardless of the filtering method used. We also report measures of business cycle asymmetry, since the shocks from the $A$ process have the potential of being highly skewed, especially in our parameterization of the model. We use Sichel's (1993) measures of deepness and steepness, which are the skewness of the series and the skewness of its first-difference, respectively. In this case, of course, the shocks are not skewed, since the innovations to $z$ are normally distributed, and with a 
few exceptions, the deepness and steepness measures are not significantly different from the US measures.

There are two sources of aggregate fluctuations in our model: an aggregate effect working through technology in each sector that will be non-zero if there are a small number of sectors, $A$, and other shocks to productivity which could proxy for a variety of things, $z$. Our next attempt is to see how well a model driven only by the Schumpeterian source of shocks does in fitting the US moments. The results of this model, where we set $I$ to the extreme value of one, and $\sigma$ equal to zero, are presented in table 5. As that table shows, the fit is considerably worse than the simple exogenous shock model. The volatility of consumption is ridiculously high for all filtering methods. In addition, the model matches the business cycle asymmetries only for very low frequency movements. In terms of other moments it does no better than the exogenous shock case. We conclude that our model as presently setup is not any an improvement in terms of its ability to match business cycle moments.

We next consider a version of our model driven entirely by exogenous shocks. This is not the same as the model in table 4, however, since our model allows for these exogenous shocks to influence the allocation of labor or production and R\&D. There is an additional transmission mechanism that is missing in the first case. The results of setting $I$ equal to 1 million and $\sigma$ to the same value as table 4 , are reported in table 6 . The only substantive difference this model yields is a drop in the volatility of investment at all frequencies. Since investment volatility is already too small, this is not an encouraging development.

Finally, we consider a version of the model where shocks come from both sources. We set $I$ to ten and $\sigma$ to .0175 . In terms of the volatility, the exogenous shocks are by far the most important source of variation., but the contribution of endogenous shocks is still nontrivial. These results are in table 7. Consumption volatility is still too high, and higher than the first model. Investment volatility is too low and lower than the first model. This model does just as well in terms of asymmetries, and slightly better in terms of matching correlations with leads and lags of output. But the overall fit is not overwhelmingly better or worse. 
In order to formalize our comparison of moments across we compute measures of the percentage deviations of the models moments from the US data moments. We report both the root mean squared deviation (RMSD), and the mean absolute deviations (MAD) for two sets of moments.

The first set of moments is the volatility of output, the relative volatility of consumption, the relative volatility of investment, and the contemporaneous correlations of consumption and investment with output. These are reported in the top panel of table 8. As can be seen the simple exogenous shock model with no R\&D is clearly the best fitting model. The version of our model with only exogenous shocks fits almost as well. The two shock model is a bit worse and the model with only Schumpeterian shocks has a very bad fit.

If we use all the reported moments we get the values in the bottom panel. Here the results are identical to the first table when the HP-filter is used. Surprisingly, the results are different if one uses the band pass filter. In this case the two-shock version fits best, the exogenous shock version with $R \& D$ is generally second best, and the no-R\&D model is third best. The Schumpeterian shocks only model is fourth, though it is not bad in relative terms as in the top panel.

\section{Conclusions}

In this paper, we are trying to discover if the process of creative destruction used in Schumpeterian models of growth is a reasonable source for the technology shocks used to drive business cycles, particularly in the context of RBC models. We conclude that the process alone is not appropriate. In our simple model with no labor-leisure choice and no diffusion mechanism for these technology shocks, we find that in order to generate realistic volatilities for output we also generate highly counterfactual volatilities of consumption and investment, and that we fail to match observed business cycle asymmetries.

We also show that versions of our model which rely heavily on exogenous symmetric shocks fail to match consumption and investment movements any better than an equivalent RBC model with no Schumpeterian mechanism. 
On the other hand, we do find that when we consider correlations of consumption and investment with output leads and lags, our model matches moments better than the simple RBC model, at least when a band pass filtering method is used.

As a result we conclude that further exploration of the potential contribution of Schumpeterian shocks to business cycle and other aggregate fluctuations is worth considering. While this model cannot fit the US moments as well as many RBC models, it is likely that this failure can be attributed in large part, to the lack of sophistication in modeling the nonSchumpeterian aspects of the model. In particular, we do not have any sort of labor-leisure decision in our model. Allowing for this type of substitution would go a long way in dampening the volatility of consumption our model generates. In addition, our model does not incorporate any sort of R\&D spillovers or technological diffusion of innovations across sectors. These may well be important and will undoubtedly change the aggregate behavior of output, investment \& consumption.

Because of this lack of diffusion we are forced to drive changes in aggregate output by assuming a small number of intermediate goods sectors. It may be more profitable to build a model with a large number of intermediate sectors generating approximately smooth growth, and consider innovations which affect all industries equally as coming from some other source. In earlier related work, we were able to generate more realistic models when we allowed for movements in basic research to be distinct from movements in applied research, for example. 
Table 1

\section{Definition of Variables}

Endogenous variables that change over time:

$A_{i} \quad$ level of applied knowledge in intermediate industry $i$

$A \quad$ aggregate level of applied knowledge

$Z \quad$ aggregate RBC-style productivity shock

$K \quad$ capital stock owned by household

$K_{i} \quad$ capital employed in industry

$P_{i} \quad$ shares of production firm $i$ owned by household ( 1 in equilibrium)

$R_{i} \quad$ shares of research firm $i$ owned by household ( 1 in equilibrium)

$S_{i} \quad$ state of research success for industry $i, 1$ is success, 0 is failure

$W \quad$ real wage

$r \quad$ real interest rate

$L_{i} \quad$ labor hired by research firm $i$ (same for all $i$ in equilibrium)

$L \quad$ aggregate labor hired by all R\&D firms

$N_{i} \quad$ labor hired by production firm $i$ (same for all $i$ in equilibrium)

$N \quad$ aggregate labor hired by all production firms

$Y_{i} \quad$ output of intermediate good $i$

$Y \quad$ output of final goods

$p_{i} \quad$ price of intermediate good $i$

$\pi_{i} \quad$ profits earned by current production firm $i$ (same for all $i$ in equilibrium)

$q_{i}^{P} \quad$ price of one share in the current production firm $i$ (same for all $i$ in equilibrium)

$q_{i}^{R} \quad$ price of one share in the current research firm $i$ (same for all $i$ in equilibrium)

$\rho_{i} \quad$ probability that $S_{i}^{\prime}=1$ (same for all $i$ in equilibrium)

$I \quad$ number of industries in the economy

$J \quad$ number of industries that successfully innovate; $J \leq I$

$\eta \quad$ random innovations to $\mathrm{z}$

\section{Parameters:}

$\alpha \quad$ capital share in output from a Cobb-Douglas production function; $0<\alpha<1$.

$\beta \quad$ time discount factor; $\beta<1$.

$\gamma \quad$ CES parameter from momentary utility function; $\gamma>0$.

$\delta \quad$ rate of depreciation; $\delta>0$.

$\theta \quad$ growth factor for $A_{i}$ when $S_{i}=1 ; \theta>1$.

$\kappa \quad$ sensitivity of $\rho$ to R\&D inputs; $\kappa>0$.

$\psi \quad$ autocorrelation parameter for $z$.

$\sigma^{2} \quad$ variance of innovations in $z$. 
Table 2

\section{Values of Parameters Used in Simulations}

\begin{tabular}{|l|l|l|}
\hline Parameter & Description & Value \\
\hline$\alpha$ & Capital share in GDP & 0.30 \\
\hline$\beta$ & Time discount factor for utility & 0.995 \\
\hline$\delta$ & Depreciation rate & 0.02 \\
\hline$\theta$ & Size of rungs on the applied technology ladder & 1.04877 \\
\hline$\gamma$ & Elasticity of substitution & 0.1397 \\
\hline$\kappa$ & Ease of R\&D & 3.390 \\
\hline$\psi$ & Autocorrelation for $z$ shocks & 0.95 \\
\hline$I$ & Number of Intermediate Goods Sectors & 1 to $1,000,000$ \\
\hline$\sigma$ & Standard deviation of z innovations & 0 to .01836 \\
\hline
\end{tabular}


Table 3

Moments from U.S. Data (1947:I-2002:IV)*

\begin{tabular}{|c|c|c|c|c|c|c|c|}
\hline HP Filter $(\lambda=1600)$ & $\mathrm{Y}$ & $\mathrm{C}$ & I & Band Pass $(6,32)$ & $\mathrm{Y}$ & $\mathrm{C}$ & I \\
\hline Standard deviation & 0.0175 & 0.0135 & 0.1025 & Standard deviation & 0.0149 & 0.0121 & 0.0759 \\
\hline Relative to Y & 1 & 0.7724 & 5.8523 & Relative to Y & 1 & 0.8140 & 5.1020 \\
\hline Steepness & -0.6060 & -0.2555 & 0.1292 & Steepness & -0.4496 & -0.3064 & 0.3299 \\
\hline Deepness & -0.0847 & -0.2262 & 0.0004 & Deepness & -0.2630 & 0.2352 & 1.3217 \\
\hline Correlation with $\mathrm{Y}+4$ & 0.0747 & 0.2480 & 0.0107 & Correlation with $\mathrm{Y}+4$ & 0.0399 & 0.1787 & 0.1318 \\
\hline Correlation with $\mathrm{Y}+3$ & 0.3249 & 0.3997 & 0.2105 & Correlation with $\mathrm{Y}+3$ & 0.3373 & 0.4087 & 0.3317 \\
\hline Correlation with $\mathrm{Y}+2$ & 0.6030 & 0.5494 & 0.4047 & Correlation with $\mathrm{Y}+2$ & 0.6568 & 0.6140 & 0.5252 \\
\hline Correlation with $\mathrm{Y}+1$ & 0.8449 & 0.6319 & 0.5310 & Correlation with $\mathrm{Y}+1$ & 0.9054 & 0.7146 & 0.6123 \\
\hline Correlation with Y & 1 & 0.5880 & 0.5382 & Correlation with Y & 1 & 0.6545 & 0.5217 \\
\hline Correlation with Y-1 & 0.8450 & 0.3698 & 0.2738 & Correlation with Y-1 & 0.9054 & 0.4394 & 0.2704 \\
\hline Correlation with Y-2 & 0.6020 & 0.0964 & -0.0400 & Correlation with Y-2 & 0.6568 & 0.1293 & -0.0610 \\
\hline Correlation with Y-3 & 0.3238 & -0.1774 & -0.3093 & Correlation with Y-3 & 0.3373 & -0.1830 & -0.3595 \\
\hline Correlation with Y-4 & 0.0758 & -0.3532 & -0.4781 & Correlation with Y-4 & 0.0399 & -0.4081 & -0.5298 \\
\hline Band Pass $(2,6)$ & & & & Band Pass $(20,80)$ & & & \\
\hline Standard deviation & 0.0041 & 0.0045 & 0.0336 & Standard deviation & 0.0133 & 0.0084 & 0.0365 \\
\hline Relative to Y & 1 & 1.0819 & 8.1586 & Relative to $\mathrm{Y}$ & 1 & 0.6335 & 2.7418 \\
\hline Steepness & -0.2638 & 0.1477 & -0.0905 & Steepness & -0.0763 & 0.0329 & 0.2348 \\
\hline Deepness & 0.2261 & -0.1537 & -0.0754 & Deepness & -0.6442 & -0.7053 & -0.6322 \\
\hline Correlation with $\mathrm{Y}+4$ & 0.1619 & 0.2376 & 0.0341 & Correlation with $\mathrm{Y}+4$ & 0.6288 & 0.6416 & 0.5880 \\
\hline Correlation with $\mathrm{Y}+3$ & -0.1730 & -0.1468 & 0.0344 & Correlation with $\mathrm{Y}+3$ & 0.7754 & 0.6968 & 0.6141 \\
\hline Correlation with $\mathrm{Y}+2$ & -0.4161 & -0.1535 & -0.3033 & Correlation with $\mathrm{Y}+2$ & 0.8922 & 0.7158 & 0.6011 \\
\hline Correlation with $\mathrm{Y}+1$ & -0.0955 & -0.0079 & -0.1409 & Correlation with $\mathrm{Y}+1$ & 0.9695 & 0.6974 & 0.5461 \\
\hline Correlation with Y & 1 & 0.2879 & 0.5004 & Correlation with Y & 1 & 0.6435 & 0.4516 \\
\hline Correlation with Y-1 & -0.0955 & 0.0093 & -0.0243 & Correlation with Y-1 & 0.9695 & 0.5451 & 0.3216 \\
\hline Correlation with Y-2 & -0.4161 & -0.0613 & -0.0808 & Correlation with Y-2 & 0.8922 & 0.4222 & 0.1774 \\
\hline Correlation with Y-3 & -0.1730 & 0.0028 & -0.1034 & Correlation with Y-3 & 0.7754 & 0.2867 & 0.0324 \\
\hline Correlation with Y-4 & 0.1619 & -0.2520 & -0.2141 & Correlation with Y-4 & 0.6288 & 0.1503 & -0.1007 \\
\hline
\end{tabular}

* Source: Bureau of Economic Analysis. 
Table 4

Moments from a pure exogenous shock version of our model (Model 1)

$$
\alpha=.3, \beta=.995, \gamma=.1397, \delta=.02, \psi=.95, \sigma=.018364
$$

\begin{tabular}{|c|c|c|c|c|c|c|c|}
\hline HP Filter $(\lambda=1600)$ & $\mathrm{Y}$ & $\mathrm{C}$ & I & Band Pass $(6,32)$ & $\mathrm{Y}$ & $\mathrm{C}$ & I \\
\hline Standard deviation & 0.0175 & $0.0251 * * *$ & $0.0625 * * *$ & Standard deviation & 0.0145 & $0.0157 * *$ & $0.0516 * * *$ \\
\hline Relative to Y & 1 & $1.4457 * * *$ & $3.5830 * * *$ & Relative to $\mathrm{Y}$ & 1 & $1.0854 * * *$ & $3.5579 * * *$ \\
\hline Steepness & $0.0010 * * *$ & -0.0687 & -0.2119 & Steepness & 0.0073 & -0.0396 & $-0.1734 *$ \\
\hline Deepness & 0.0035 & 0.0045 & -0.0086 & Deepness & 0.0079 & $0.0083 * * *$ & $-0.0124 * * *$ \\
\hline Correlation with $\mathrm{Y}+4$ & 0.1115 & $-0.3136 * * *$ & $0.3613 * * *$ & Correlation with $\mathrm{Y}+4$ & 0.0282 & $-0.6116 * * *$ & $0.4164 * * *$ \\
\hline Correlation with $\mathrm{Y}+3$ & 0.2741 & $-0.3495 * * *$ & $0.5332 * * *$ & Correlation with $\mathrm{Y}+3$ & 0.3012 & $-0.6929 * * *$ & $0.7075 * * *$ \\
\hline Correlation with $\mathrm{Y}+2$ & $0.4755^{*}$ & $-0.3778 * * *$ & $0.7329 * * *$ & Correlation with $\mathrm{Y}+2$ & 0.6241 & $-0.5821 * * *$ & $0.9188 * * *$ \\
\hline Correlation with $\mathrm{Y}+1$ & $0.7174 * * *$ & $-0.3946 * * *$ & $0.9585 * * *$ & Correlation with $\mathrm{Y}+1$ & 0.8921 & $-0.2664 * * *$ & $0.9503 * * *$ \\
\hline Correlation with Y & 1 & $0.3246 * * *$ & 0.5915 & Correlation with Y & 1 & $0.1603 * * *$ & $0.7705 * * *$ \\
\hline Correlation with Y-1 & $0.7173 * * *$ & 0.3810 & 0.2997 & Correlation with Y-1 & 0.8921 & $0.5373 * * *$ & $0.4346 * * *$ \\
\hline Correlation with Y-2 & $0.4756^{*}$ & $0.3999 * * *$ & 0.0752 & Correlation with Y-2 & 0.6241 & $0.7380 * * *$ & $0.0724 *$ \\
\hline Correlation with Y-3 & 0.2745 & $0.3900 * * *$ & $-0.0898 * * *$ & Correlation with Y-3 & 0.3012 & $0.7354 * * *$ & $-0.2070^{*}$ \\
\hline Correlation with Y-4 & 0.1123 & $0.3601 * * *$ & $-0.2045^{* * *}$ & Correlation with Y-4 & 0.0282 & $0.5983 * * *$ & $-0.3565 * *$ \\
\hline Band Pass $(2,6)$ & & & & Band Pass $(20,80)$ & & & \\
\hline Standard deviation & $0.0067 * * *$ & $0.0174 * * *$ & $0.0255 * * *$ & Standard deviation & 0.0136 & $0.0126 * *$ & 0.0433 \\
\hline Relative to Y & 1 & $2.6093 * * *$ & $3.8161 * * *$ & Relative to $\mathrm{Y}$ & 1 & $0.9303 * * *$ & $3.1866 * * *$ \\
\hline Steepness & -0.0095 & -0.0377 & -0.0931 & Steepness & -0.0016 & -0.0075 & -0.0901 \\
\hline Deepness & 0.0073 & -0.0039 & 0.0058 & Deepness & 0.0421 & $-0.0306 * * *$ & $0.0558 * * *$ \\
\hline Correlation with $\mathrm{Y}+4$ & 0.1800 & 0.1791 & -0.1092 & Correlation with $\mathrm{Y}+4$ & 0.6539 & $-0.4095 * * *$ & $0.8891 * * *$ \\
\hline Correlation with $\mathrm{Y}+3$ & -0.0922 & $0.2155 * * *$ & $-0.3842 * * *$ & Correlation with $\mathrm{Y}+3$ & 0.7903 & $-0.2707 * * *$ & $0.9367 * * *$ \\
\hline Correlation with $\mathrm{Y}+2$ & -0.3918 & -0.1014 & -0.1764 & Correlation with $\mathrm{Y}+2$ & 0.8987 & $-0.1053 * * *$ & $0.9407 * * *$ \\
\hline Correlation with $\mathrm{Y}+1$ & $-0.2081 *$ & $-0.8058 * * *$ & $0.9879 * * *$ & Correlation with $\mathrm{Y}+1$ & 0.9709 & $0.0799 * * *$ & $0.8974 * * *$ \\
\hline Correlation with Y & 1 & $0.7406 * * *$ & $-0.2484 * * *$ & Correlation with Y & 1 & $0.2765 * * *$ & $0.8053 * * *$ \\
\hline Correlation with Y-1 & $-0.2081 *$ & $0.1640 *$ & $-0.4029 * * *$ & Correlation with Y-1 & 0.9709 & $0.4596 * *$ & $0.6647 * * *$ \\
\hline Correlation with Y-2 & -0.3918 & -0.1669 & -0.0806 & Correlation with Y-2 & 0.8987 & $0.6199 * * *$ & $0.4963 * * *$ \\
\hline Correlation with Y-3 & -0.0922 & $-0.1844 * *$ & $0.1879 * * *$ & Correlation with Y-3 & 0.7903 & $0.7497 * * *$ & $0.3114 * * *$ \\
\hline Correlation with Y-4 & 0.1800 & $-0.0274 * * *$ & $0.1860 * * *$ & Correlation with Y-4 & 0.6539 & $0.8434 * * *$ & $0.1214 * * *$ \\
\hline
\end{tabular}

* significantly different from the corresponding US data moment at $90 \%$ confidence

** significantly different from the corresponding US data moment at $95 \%$ confidence

*** significantly different from the corresponding US data moment at $99 \%$ confidence 
Table 5

Moments from our model driven only by $A$ shocks (Model 2)

$$
\alpha=.3, \beta=.995, \gamma=.1397, \delta=.02, \theta=1.04877, I=1, \psi=.95, \sigma=0
$$

\begin{tabular}{|c|c|c|c|c|c|c|c|}
\hline HP Filter $(\lambda=1600)$ & Y & $\mathrm{C}$ & I & Band Pass (6,32) & Y & $\mathrm{C}$ & I \\
\hline Standard deviation & 0.0185 & $0.1043^{* * *}$ & $0.0613^{* * *}$ & Standard deviation & 0.0154 & $0.0543 * * *$ & $0.0326 * * *$ \\
\hline Relative to Y & 1 & $5.6600 * * *$ & $3.3293 * * *$ & Relative to Y & 1 & $3.5279 * * *$ & $2.1166 * * *$ \\
\hline Steepness & $-0.0733 * * *$ & $-1.6703 * * *$ & $1.6070 * * *$ & Steepness & -0.0643 & -0.5754 & 0.5042 \\
\hline Deepness & $1.6699 * * *$ & $0.0342 * * *$ & $0.2487 * * *$ & Deepness & $0.4825 * *$ & 0.0251 & $0.1385 * * *$ \\
\hline Correlation with $\mathrm{Y}+4$ & 0.1198 & $-0.2193 * * *$ & $0.2602 * * *$ & Correlation with $\mathrm{Y}+4$ & 0.0430 & $-0.5836^{* * *}$ & $0.6270 * * *$ \\
\hline Correlation with $\mathrm{Y}+3$ & 0.2799 & $-0.2570 * * *$ & $0.3326^{* *}$ & Correlation with $\mathrm{Y}+3$ & 0.3115 & $-0.6582 * * *$ & $0.7897 * * *$ \\
\hline Correlation with $\mathrm{Y}+2$ & $0.4775^{*}$ & $-0.2915^{* * *}$ & 0.4090 & Correlation with $\mathrm{Y}+2$ & 0.6294 & $-0.5127 * * *$ & $0.7376^{* * *}$ \\
\hline Correlation with $\mathrm{Y}+1$ & $0.7134 * * *$ & $-0.3369 * * *$ & 0.5043 & Correlation with $\mathrm{Y}+1$ & 0.8935 & $-0.1525 * * *$ & $0.4443 * * *$ \\
\hline Correlation with Y & 1 & $0.4154 * * *$ & $-0.2408 * * *$ & Correlation with Y & 1 & $0.2943 * * *$ & $0.0107 * * *$ \\
\hline Correlation with Y-1 & 0.7134 & 0.3599 & $-0.2375 * * *$ & Correlation with Y-1 & 0.8935 & $0.6380 * * *$ & $-0.3825 * * *$ \\
\hline Correlation with Y-2 & $0.4774 *$ & $0.3090 * * *$ & $-0.2321 * * *$ & Correlation with Y-2 & 0.6294 & $0.7544 * * *$ & $-0.5882 * * *$ \\
\hline Correlation with Y-3 & 0.2798 & $0.2560 * * *$ & $-0.2168^{*}$ & Correlation with Y-3 & 0.3115 & $0.6462 * * *$ & $-0.5768 * * *$ \\
\hline Correlation with Y-4 & 0.1195 & $0.2045^{* * *}$ & $-0.1952 * * *$ & Correlation with Y-4 & 0.0430 & $0.4231 * * *$ & -0.4302 \\
\hline Band Pass $(\mathbf{2 , 6 )}$ & & & & Band Pass $(20,80)$ & & & \\
\hline Standard deviation & $0.0072 * * *$ & $0.0821 * * *$ & $0.0478 * * *$ & Standard deviation & 0.0149 & $0.0288 * * *$ & $0.0178 * * *$ \\
\hline Relative to Y & 1 & $11.4759 * * *$ & $6.6875^{* * *}$ & Relative to $\mathrm{Y}$ & 1 & $1.9417 * * *$ & $1.2008 * * *$ \\
\hline Steepness & $-0.0055 * * *$ & $-0.8764 * * *$ & $0.8835 * * *$ & Steepness & -0.0307 & -0.1070 & 0.0880 \\
\hline Deepness & $0.8699 * * *$ & $0.0202 * * *$ & $0.1019 * * *$ & Deepness & -0.0059 & -0.0224 & -0.0992 \\
\hline Correlation with $\mathrm{Y}+4$ & 0.1771 & 0.1705 & -0.1654 & Correlation with $\mathrm{Y}+4$ & 0.6707 & $-0.4034 * * *$ & $0.7902 * * *$ \\
\hline Correlation with $\mathrm{Y}+3$ & -0.0838 & $0.1869 * * *$ & $-0.2090 * * *$ & Correlation with $\mathrm{Y}+3$ & 0.8005 & $-0.2545 * * *$ & $0.7093 * *$ \\
\hline Correlation with $\mathrm{Y}+2$ & -0.3784 & -0.1101 & $0.0808 * * *$ & Correlation with $\mathrm{Y}+2$ & 0.9036 & $-0.0786^{* * *}$ & 0.5858 \\
\hline Correlation with $\mathrm{Y}+1$ & $-0.2170 * *$ & $-0.7738 * * *$ & $0.8100 * * *$ & Correlation with $\mathrm{Y}+1$ & 0.9722 & $0.1166^{* * *}$ & $0.4233 * * *$ \\
\hline Correlation with Y & 1 & $0.7823 * * *$ & $-0.7433 * * *$ & Correlation with Y & 1 & $0.3224 * * *$ & $0.2276^{* * *}$ \\
\hline Correlation with Y-1 & $-0.2170 * *$ & 0.1115 & -0.1388 & Correlation with Y-1 & 0.9722 & $0.5022 *$ & $0.0273 * * *$ \\
\hline Correlation with Y-2 & -0.3784 & $-0.1913 *$ & $0.1677 * * *$ & Correlation with Y-2 & 0.9036 & $0.6498 * * *$ & $-0.1628 * * *$ \\
\hline Correlation with Y-3 & -0.0838 & $-0.1710 * *$ & $0.1745^{* * *}$ & Correlation with Y-3 & 0.8005 & $0.7597 * * *$ & $-0.3334 * * *$ \\
\hline Correlation with Y-4 & 0.1771 & $-0.0048 * * *$ & $0.0224 * * *$ & Correlation with Y-4 & 0.6707 & $0.8283 * * *$ & $-0.4768 * * *$ \\
\hline
\end{tabular}

* significantly different from the corresponding US data moment at $90 \%$ confidence

** significantly different from the corresponding US data moment at $95 \%$ confidence

*** significantly different from the corresponding US data moment at $99 \%$ confidence 
Table 6

Moments from our model driven only by $z$ shocks (Model 3)

$$
\alpha=.3, \beta=.995, \gamma=.1397, \delta=.02, \theta=1.04877, I=1,000,000, \psi=.95, \sigma=.018364
$$

\begin{tabular}{|c|c|c|c|c|c|c|c|}
\hline HP Filter $(\lambda=1600)$ & Y & $\mathrm{C}$ & I & Band Pass $(6,32)$ & $\mathrm{Y}$ & $\mathrm{C}$ & I \\
\hline Standard deviation & 0.0175 & $0.0247 * * *$ & $0.0169 * * *$ & Standard deviation & 0.0145 & $0.0154 * *$ & $0.0129 * * *$ \\
\hline Relative to Y & 1 & $1.4171 * * *$ & $0.9678 * * *$ & Relative to Y & 1 & $1.0589 * * *$ & $0.8877 * * *$ \\
\hline Steepness & $0.0098 * * *$ & -0.0694 & -0.0381 & Steepness & 0.0065 & -0.0408 & -0.0633 \\
\hline Deepness & 0.0041 & 0.0125 & 0.0329 & Deepness & -0.0100 & 0.0075 & $0.0091 * * *$ \\
\hline Correlation with $\mathrm{Y}+4$ & 0.1169 & $-0.3051 * * *$ & $0.3877 * * *$ & Correlation with $\mathrm{Y}+4$ & 0.0359 & $-0.6043 * * *$ & $0.5218 * * *$ \\
\hline Correlation with $\mathrm{Y}+3$ & 0.2783 & $-0.3315^{* * *}$ & $0.5286^{* * *}$ & Correlation with $\mathrm{Y}+3$ & 0.3074 & $-0.6687 * * *$ & $0.7835 * * *$ \\
\hline Correlation with $\mathrm{Y}+2$ & 0.4763 & $-0.3537 * * *$ & $0.6912 * * *$ & Correlation with $\mathrm{Y}+2$ & 0.6275 & $-0.5430 * * *$ & $0.9264 * * *$ \\
\hline Correlation with $\mathrm{Y}+1$ & $0.7168 * * *$ & $-0.3638 * * *$ & $0.8716^{* * *}$ & Correlation with $\mathrm{Y}+1$ & 0.8930 & $-0.2192 * * *$ & $0.8647 * * *$ \\
\hline Correlation with Y & 1 & $0.3569 * * *$ & $0.3449 * * *$ & Correlation with Y & 1 & $0.2061 * * *$ & $0.5982 * * *$ \\
\hline Correlation with Y-1 & $0.7170 * * *$ & 0.4019 & $0.1025^{* * *}$ & Correlation with Y-1 & 0.8930 & $0.5732 * * *$ & 0.2157 \\
\hline Correlation with Y-2 & 0.4767 & $0.4102 * * *$ & -0.0735 & Correlation with Y-2 & 0.6275 & $0.7601 * * *$ & -0.1402 \\
\hline Correlation with Y-3 & 0.2788 & $0.3962 * * *$ & $-0.1980 *$ & Correlation with Y-3 & 0.3074 & $0.7453 * * *$ & -0.3723 \\
\hline Correlation with Y-4 & 0.1174 & $0.3632 * * *$ & $-0.2785 * * *$ & Correlation with Y-4 & 0.0359 & $0.6010 * * *$ & -0.4614 \\
\hline Band Pass $(2,6)$ & & & & Band Pass $(20,80)$ & & & \\
\hline Standard deviation & $0.0067 * * *$ & $0.0172 * * *$ & $0.0089 * * *$ & Standard deviation & 0.0137 & $0.0125^{*}$ & $0.0104 * * *$ \\
\hline Relative to Y & 1 & 2.5603 & $1.3242 * * *$ & Relative to $\mathrm{Y}$ & 1 & $0.9156^{* * *}$ & $0.7582 * * *$ \\
\hline Steepness & -0.0089 & -0.0348 & 0.0062 & Steepness & -0.0116 & -0.0439 & -0.0227 \\
\hline Deepness & 0.0023 & 0.0003 & 0.0190 & Deepness & -0.0545 & -0.0066 & -0.0213 \\
\hline Correlation with $\mathrm{Y}+4$ & 0.1799 & 0.1754 & -0.1392 & Correlation with $\mathrm{Y}+4$ & 0.6551 & $-0.3636 * * *$ & $0.8877 * * *$ \\
\hline Correlation with $\mathrm{Y}+3$ & -0.0860 & $0.2144 * * *$ & $-0.3288 * * *$ & Correlation with $\mathrm{Y}+3$ & 0.7912 & $-0.2194 * * *$ & $0.8902 * * *$ \\
\hline Correlation with Y+2 & -0.3920 & -0.1057 & $-0.0630 * * *$ & Correlation with $\mathrm{Y}+2$ & 0.8992 & $-0.0508 * * *$ & $0.8475 * * *$ \\
\hline Correlation with $\mathrm{Y}+1$ & $-0.2101 * *$ & $-0.7993 * * *$ & $0.9522 * * *$ & Correlation with $\mathrm{Y}+1$ & 0.9711 & $0.1352 * * *$ & $0.7582 * * *$ \\
\hline Correlation with Y & 1 & $0.7495 * * *$ & $-0.4796 * * *$ & Correlation with Y & 1 & $0.3299 * * *$ & $0.6234 * * *$ \\
\hline Correlation with Y-1 & $-0.2101 * *$ & $0.1569 *$ & $-0.3147 * * *$ & Correlation with Y-1 & 0.9711 & 0.5080 & $0.4504 * * *$ \\
\hline Correlation with Y-2 & -0.3920 & -0.1758 & 0.0311 & Correlation with Y-2 & 0.8992 & $0.6615 * * *$ & $0.2596 * * *$ \\
\hline Correlation with Y-3 & -0.0860 & $-0.1798 * *$ & $0.1932 * * *$ & Correlation with Y-3 & 0.7912 & $0.7830 * * *$ & 0.0627 \\
\hline Correlation with Y-4 & 0.1799 & $-0.0189 * * *$ & $0.1173 * * *$ & Correlation with Y-4 & 0.6551 & $0.8675 * * *$ & -0.1287 \\
\hline
\end{tabular}

\footnotetext{
* significantly different from the corresponding US data moment at $90 \%$ confidence

** significantly different from the corresponding US data moment at $95 \%$ confidence

*** significantly different from the corresponding US data moment at $99 \%$ confidence
} 
Table 7

Moments from our model driven by a combination of $A \& z$ shocks (Model 4) $\alpha=.3, \beta=.995, \gamma=.1397, \delta=.02, \theta=1.04877, I=10, \psi=.95, \sigma=.0175$

\begin{tabular}{|c|c|c|c|c|c|c|c|}
\hline HP Filter $(\lambda=1600)$ & Y & $\mathrm{C}$ & I & Band Pass $(6,32)$ & $\mathrm{Y}$ & $\mathrm{C}$ & I \\
\hline Standard deviation & 0.0177 & $0.0394 * * *$ & $0.0258 * * *$ & Standard deviation & 0.0148 & $0.0221 * * *$ & $0.0163 * * *$ \\
\hline Relative to Y & 1 & $2.2379 * * *$ & $1.4645 * * *$ & Relative to $\mathrm{Y}$ & 1 & $1.5018 * * *$ & $1.1089 * * *$ \\
\hline Steepness & $-0.0051 * * *$ & -0.3345 & 0.1751 & Steepness & -0.0053 & -0.1159 & -0.0160 \\
\hline Deepness & 0.0170 & $0.0068 *$ & 0.0641 & Deepness & 0.0021 & 0.0091 & $0.0193 * * *$ \\
\hline Correlation with $\mathrm{Y}+4$ & 0.1161 & $-0.2332 * * *$ & $0.2990 * * *$ & Correlation with $\mathrm{Y}+4$ & 0.0348 & $-0.5274 * * *$ & $0.5115^{* * *}$ \\
\hline Correlation with $\mathrm{Y}+3$ & 0.2788 & $-0.2548 * * *$ & $0.3978 * * *$ & Correlation with $\mathrm{Y}+3$ & 0.3071 & $-0.5845 * * *$ & $0.7321 * * *$ \\
\hline Correlation with $\mathrm{Y}+2$ & $0.4764 *$ & $-0.2778 * * *$ & $0.5143 * *$ & Correlation with $\mathrm{Y}+2$ & 0.6278 & $-0.4677 * * *$ & $0.8208 * * *$ \\
\hline Correlation with $\mathrm{Y}+1$ & $0.7164 * * *$ & $-0.2941 * * *$ & $0.6433 * * *$ & Correlation with $\mathrm{Y}+1$ & 0.8933 & $-0.1741 * * *$ & $0.7115^{* * *}$ \\
\hline Correlation with Y & 1 & $0.3126 * * *$ & $0.1401 * * *$ & Correlation with Y & 1 & $0.2039 * * *$ & 0.4264 \\
\hline Correlation with Y-1 & $0.7162 * * *$ & 0.3242 & $-0.0026 * * *$ & Correlation with Y-1 & 0.8933 & 0.5202 & $0.0682 * *$ \\
\hline Correlation with Y-2 & $0.4762 *$ & $0.3155 * * *$ & -0.1049 & Correlation with Y-2 & 0.6278 & $0.6679 * * *$ & $-0.2310 * *$ \\
\hline Correlation with Y-3 & 0.2787 & $0.2937 * * *$ & $-0.1743 * * *$ & Correlation with Y-3 & 0.3071 & $0.6333 * * *$ & -0.3951 \\
\hline Correlation with Y-4 & 0.1163 & $0.2625 * * *$ & $-0.2177 * * *$ & Correlation with Y-4 & 0.0348 & $0.4874 * * *$ & -0.4269 \\
\hline Band Pass $(2,6)$ & & & & Band Pass $(20,80)$ & & & \\
\hline Standard deviation & $0.0068 * * *$ & $0.0298 * * *$ & $0.0179 * * *$ & Standard deviation & 0.0139 & $0.0148 * * *$ & $0.0115 * * *$ \\
\hline Relative to Y & 1 & $4.3853 * * *$ & $2.6319 * * *$ & Relative to $\mathrm{Y}$ & 1 & $1.0699 * * *$ & $0.8279 * * *$ \\
\hline Steepness & -0.0021 & -0.2002 & 0.1751 & Steepness & -0.0138 & -0.0220 & -0.0367 \\
\hline Deepness & 0.0108 & 0.0024 & 0.0295 & Deepness & -0.0713 & -0.0386 & 0.0081 \\
\hline Correlation with $\mathrm{Y}+4$ & 0.1825 & 0.1378 & -0.1095 & Correlation with $\mathrm{Y}+4$ & 0.6553 & $-0.3572 * * *$ & $0.8561 * * *$ \\
\hline Correlation with $\mathrm{Y}+3$ & -0.0824 & $0.1694 * * *$ & $-0.2146 * * *$ & Correlation with $\mathrm{Y}+3$ & 0.7913 & $-0.2179 * * *$ & $0.8443 * * *$ \\
\hline Correlation with $\mathrm{Y}+2$ & -0.3932 & -0.0885 & $-0.0015 * * *$ & Correlation with $\mathrm{Y}+2$ & 0.8992 & $-0.0545 * * *$ & $0.7883 * * *$ \\
\hline Correlation with $\mathrm{Y}+1$ & $-0.2114 * *$ & $-0.6310 * * *$ & $0.6645 * * *$ & Correlation with $\mathrm{Y}+1$ & 0.9710 & $0.1259 * * *$ & $0.6876^{* * *}$ \\
\hline Correlation with Y & 1 & $0.6069 * * *$ & $-0.4326 * * *$ & Correlation with Y & 1 & $0.3151 * * *$ & $0.5441^{*}$ \\
\hline Correlation with Y-1 & $-0.2114 * *$ & 0.1141 & -0.1839 & Correlation with Y-1 & 0.9710 & 0.4860 & 0.3692 \\
\hline Correlation with Y-2 & -0.3932 & -0.1457 & $0.0638^{*}$ & Correlation with Y-2 & 0.8992 & $0.6316 * * *$ & 0.1817 \\
\hline Correlation with Y-3 & -0.0824 & $-0.1422^{*}$ & $0.1401 * * *$ & Correlation with Y-3 & 0.7913 & $0.7451 * * *$ & -0.0071 \\
\hline Correlation with Y-4 & 0.1825 & $-0.0103 * * *$ & $0.0590 * * *$ & Correlation with Y-4 & 0.6553 & $0.8222 * * *$ & -0.1867 \\
\hline
\end{tabular}

* significantly different from the corresponding US data moment at $90 \%$ confidence

** significantly different from the corresponding US data moment at $95 \%$ confidence

$* * *$ significantly different from the corresponding US data moment at $99 \%$ confidence 
Table 8

Comparison of Fit Various Models

Based on Five Key Moments

$$
\left(\sigma_{Y}, \frac{\sigma_{C}}{\sigma_{Y}}, \frac{\sigma_{C}}{\sigma_{Y}}, \rho_{Y C}, \rho_{Y I}\right)
$$

$\begin{array}{llrrrr} & & \text { Model 1 } & \text { Model 2 } & \text { Model 3 } & \text { Model 4 } \\ \text { HP Filter ( } \mathbf{\lambda = 1 6 0 0 )} & \text { RMSD } & \mathbf{0 . 5 2 9} & 3.256 & 0.647 & 1.110 \\ & \text { MAD } & \mathbf{0 . 9 0 3} & 1.446 & 1.220 & 1.277 \\ \text { Band Pass (2,6) } & & & & & \\ & \text { RMSD } & \mathbf{1 . 3 2 2} & 5.036 & 1.498 & 1.903 \\ & \text { MAD } & \mathbf{1 . 3 3 0} & 1.844 & 1.562 & 1.588 \\ \text { Band Pass (6,32) } & & & & & \\ & \text { RMSD } & \mathbf{0 . 5 0 0} & 1.783 & 0.562 & 0.677 \\ & \text { MAD } & \mathbf{0 . 8 0 0} & 1.282 & 1.116 & 1.143 \\ \text { Band Pass (20,80) } & \text { RMSD } & \mathbf{0 . 5 4 4} & 1.126 & 0.525 & 0.562 \\ & \text { MAD } & \mathbf{0 . 6 0 5} & 0.921 & 0.829 & 0.832\end{array}$

Based on all Reported Moments

$\begin{array}{llrrrr} & & \text { Model 1 } & \text { Model 2 } & \text { Model 3 } & \text { Model 4 } \\ \text { HP Filter }(\boldsymbol{\lambda = 1 6 0 0 )} & \text { RMSD } & \mathbf{7 . 2 8 0} & 111.668 & 15.957 & 29.031 \\ & \text { MAD } & \mathbf{2 . 8 3 1} & 23.048 & 4.713 & 6.882 \\ \text { Band Pass (2,6) } & & & & & \\ & \text { RMSD } & 22.329 & 21.129 & 21.940 & \mathbf{1 7 . 2 5 6} \\ & \text { MAD } & 7.999 & 8.071 & 7.865 & \mathbf{6 . 3 3 3} \\ \text { Band Pass (6,32) } & \text { RMSD } & 1.853 & 2.537 & 1.863 & \mathbf{1 . 7 4 1} \\ & \text { MAD } & 1.283 & 1.678 & 1.236 & \mathbf{1 . 2 0 7} \\ \text { Band Pass (20,80) } & \text { RMSD } & 2.002 & 2.556 & 1.210 & \mathbf{1 . 1 4 0} \\ & \text { MAD } & 1.181 & 1.370 & 0.807 & \mathbf{0 . 7 6 8}\end{array}$




\section{Appendix 1}

The reward for success can be written as the expected present value of the profit stream, where this stream is discounted both by the real interest rate and by the probability of losing the monopoly to a newly successful research firm.

$$
V_{i}{ }^{\prime}=\pi_{i}{ }^{\prime}+q_{i}^{p}{ }^{\prime}=\sum_{s=t+1}^{\infty} \pi_{i, s} d_{i, s} ; d_{i, s}=\prod_{u=1}^{s} \frac{1-\rho_{i, u}}{1+r_{u+1}}
$$

where the second subscript, used in the summation and product, indicates the time period.

Future profits are a constant fraction, $\left(\theta^{1-\alpha}-1\right) / \theta^{1-\alpha}$, of production. The level of technology, $\theta A_{i}$, does not change as long as the firm is the monopoly producer. Consequently, we can rewrite the success reward as:

$$
V_{i}^{\prime}=\sum_{s=t+1}^{\infty} \frac{\theta^{1-\alpha}-1}{\theta^{1-\alpha}} p_{i, s} Y_{i, s} d_{i, s}
$$

Noting that $p_{i, s} Y_{i, s}=\frac{1}{I} Y_{s}$ gives:

$$
V_{i}^{\prime}=\frac{\theta^{1-\alpha}-1}{\theta^{1-\alpha}} \sum_{s=t+1}^{\infty} \frac{1}{I} Y_{s} d_{i, s} \quad \text { or } V_{i}^{\prime}=\frac{\theta^{1-\alpha}-1}{\theta^{1-\alpha}} M ; \quad M \equiv \frac{1}{I} \sum_{s=t+1}^{\infty} Y_{s} d_{i, s} .
$$

Since $M$ changes as aggregate output rises, with large $I$ large the expected effects of success or failure by any given research firm on $M$ will be small. Note also that $M$ will be the same for all research firms as long as $\rho$ is the same. There may be more than one solution to the system of equations that jointly determine the $M$ s and $\rho$ 's for all firms, but one solution is the symmetric one, where $M$ and $\rho$ are constant over time. 


\section{Appendix 2}

In order to induce stationarity, we take all the variables which grow at the same rate as $A$ in the previous section and divide them by $A$. This gives the following stationary variables:

$$
\begin{array}{cccc}
\hat{C} \equiv C / A & \hat{K} \equiv K / A \quad \hat{w} \equiv w / A & \hat{q}^{R} \equiv q^{R} / A \quad \hat{q}^{P} \equiv q^{P} / A \quad \hat{\pi} \equiv \pi / A \\
& g_{A}^{\prime} \equiv \widetilde{A}^{\prime} / A .
\end{array}
$$

The transformed law of motion for $A$ can be written: $g_{A}{ }^{\prime} \equiv A^{\prime} / A=\rho(\theta-1)+1+\varepsilon^{\prime}$, where $\varepsilon^{\prime}=[(J / I)-\rho](\theta-1)$, and $J$ is distributed Binomial $(I, \rho)$. Note that $E\left\{\varepsilon^{\prime}\right\}=0$ and $\operatorname{Var}\left\{\varepsilon^{\prime}\right\}=\frac{\rho(1-\rho)}{I}(\theta-1)^{2}$

Substituting (2.18) and (2.19) into the household's budget constraint, and transforming variables, gives: $\hat{C}=\hat{w}+(1-\delta+r) \hat{K}+\hat{\pi}-\hat{K}^{\prime}\left(1+g_{A}{ }^{\prime}\right)-\hat{q}^{R}$, with expected consumption when the household makes its share decisions given by: $E \hat{C} \equiv E\{\hat{C}\}=\hat{w}+(1-\delta+r) \hat{K}+\hat{\pi}-E\left\{\hat{K}^{\prime}\left(1+g_{A}{ }^{\prime}\right)\right\}-\hat{q}^{R}$. 


\section{References}

Aghion, P. and P. Howitt (1992), "A Model of Growth through Creative Destruction," Econometrica, vol. 60 no. 2, pp. 323-51.

Aghion, P. and P. Howitt (1998), Endogenous Growth Theory, MIT Press.

Andolfatto, D. and G.M. MacDonald (1998), "Technology Diffusion and Aggregate Dynamics," Review of Economic Dynamics, vol. 1, pp. 338-70.

Baxter, M. and R.G. King (1998), "Measuring Business Cycles: Approximate Band-Pass Filters for Economic Time Series," University of Virginia working paper.

Cheng, L. K. and E. Dinopoulos (1992), "Schumpeterian Growth and Stochastic Economic Fluctuations," University of Florida, working paper.

Cheng, L. K. and E. Dinopoulos (1996), "A Multisectoral General Equilibrium Model of Schumpeterian Growth and Fluctuations," Journal of Economic Dynamics and Control, vol. 20 n0. 5, pp. 905-23.

Christiano, L. (1990), “Computational Methods for Solving Variants of Fuerst's Model," Federal Reserve Bank of Minneapolis, working paper \#467.

Canova, F. (1998), "Detrending and Business Cycle Facts," Journal of Monetary Economics, vol. 41, no. 3 , pp. $475-512$.

Collard, F. (1999), "Spectral and Persistence Properties of Cyclical Growth," Journal of Economic Dynamics and Control, vol. 23, pp. 463-488.

Cooley, T., ed. (1995), Frontiers of Business Cycle Research, Princeton University Press.

Freeman, S., D.P. Hong and D. Peled (1999), "Endogenous Cycles and Growth with Indivisible Technological Developments," Review of Economic Dynamics, vol. 2, pp. 403-32.

Granger, C. W.J (1966), “The Typical Spectral Shape of an Economic Variable,” Econometrica, vol. 34, no.1, pp. 150-161.

Grossman, G.M. and E. Helpman (1991a), "Quality Ladders in the Theory of Growth," Review of Economic Studies, vol. 63, pp. 43-61.

Grossman, G.M. and E. Helpman (1991), Innovation and Growth in the Global Economy, MIT Press.

Kydland, F.E. and E.G. Prescott (1982), "Time to Build and Aggregate Fluctuations," Econometrica, vol. 50, pp. 1345-70.

Lambson, V.E. and K.L. Phillips (2003), "Schumpeterian Growth and R\&D Ties," Mimeo, Brigham Young University.

Long, J.B. and C.I. Plosser (1983), "Real Business Cycles," Journal of Political Economy, vol. 91, pp. 39-69.

Ozlu, E. (1996), "Aggregate Economic Fluctuations in Endogenous Growth Models," Journal of Macroeconomics, vol. 18, pp. 27-47. 
Sargent, T.J. (1987), Macroeconomic Theory, second edition, Academic Press.

Schlagenhauf, D.E. and J.M. Wrase (1995), "Liquidity and Real Activity in a Simple Open Economy Model," Journal of Monetary Economics, vol. 35, pp. 431-461.

Segerstrom, P.S., T.C.A. Anant, and E. Dinopoulos (1990), "A Schumpeterian Model of the Product Life Cycle,” American Economic Review, vol. 80, pp.1077-1091.

Sichel, Daniel E. (1993), "Business Cycle Asymmetry: A Deeper Look," Economic-Inquiry, vol. 31 no. 2, pp. 224-36.

Solow, R.M. (1957), "Technical Change and the Aggregate Production Function," $\underline{\text { Review of }}$ Economics and Statistics, vol. 39, no. 3, pp. 312-320.

Uhlig, Harald. (1999), "A Toolkit for Analyzing Nonlinear Dynamic Stochastic Models Easily," in Computational Methods for the Study of Dynamic Economies, Marimon and Scott, eds., Oxford University Press, pp. 30-61.

Wälde, Klaus. (2002), "The Economic Determinants of Technology Shocks in a Real Business Cycle Model," Journal of Economic Dynamics and Control, vol. 27 no. 1, pp. 1-28. 